\title{
Considering Cannabis: The Effects of Regular Cannabis Use on Neurocognition in Adolescents and Young Adults
}

\author{
Krista M. Lisdahl • Natasha E. Wright • \\ Christopher Medina-Kirchner • Kristin E. Maple • \\ Skyler Shollenbarger
}

Published online: 26 April 2014

(C) Springer International Publishing AG 2014

\begin{abstract}
Thirty-six percent of high-school seniors have used cannabis in the past year, and an alarming $6.5 \%$ smoked cannabis daily, up from $2.4 \%$ in 1993. Adolescents and emerging adults are undergoing significant neurodevelopment and animal studies suggest they may be particularly vulnerable to negative drug effects. In this review, we will provide a detailed overview of studies outlining the effects of regular (at least weekly) cannabis use on neurocognition, including studies outlining cognitive, structural, and functional findings. We will also explore the public health impact of this research.
\end{abstract}

Keywords Adolescence $\cdot$ Emerging Adult · Young Adult . Cannabis · Marijuana · MRI · fMRI · Diffusion Tensor Imaging $\cdot$ Neuropsychology $\cdot$ Cognition $\cdot$ Age of Onset . FAAH · CNR1 - THC · Cannabidiol · Public health .

Neurotoxic effects of cannabis

\section{Introduction}

Cannabis is the second most used drug after alcohol, with $22.9 \%$ of high-school seniors and $20 \%$ of college students using in the past month, and perhaps most alarmingly, one in every 15 seniors report using daily [1]. Research outlining the neurocognitive effects of chronic, regular (defined here as at least weekly) cannabis use in adolescents and young adults is of great public health concern. This review will summarize current findings regarding the neurocognitive consequences of cannabis use during the teenage and emerging adult years (focusing on ages 15-25 years). Studies utilizing

K. M. Lisdahl $(\bowtie) \cdot$ N. E. Wright • C. Medina-Kirchner

K. E. Maple $\cdot$ S. Shollenbarger

Department of Psychology, University of Wisconsin-Milwaukee,

2241 E. Hartford Ave, Milwaukee, WI 53211, USA

e-mail: krista.medina@gmail.com neuropsychological assessment and structural and functional neuroimaging will be reviewed. Further, we will identify potential 'at-risk' groups who may experience more severe neurocognitive consequences of chronic cannabis use, such as those with early age of cannabis use onset and those with certain genotypic profiles, and will discuss the clinical and policy implications of this research.

\section{Adolescence: A Sensitive Period?}

Worldwide, most people start experimenting with drugs during the teenage years [2]. Adolescence is also a dynamic time marked by significant neurodevelopmental changes; brain regions underlying higher-order thinking and executive functioning, especially the prefrontal (PFC) and parietal cortex, undergo synaptic pruning into the mid-20s (see [3-6]). Quality and volume of white matter increase into the early $30 \mathrm{~s}$, which are associated with increased neural efficiency $[7,8]$. This period of ongoing neurodevelopment may be a sensitive period in which drugs can exert a greater impact on the brain compared with exposure during adulthood (see [9]).

\section{Impacts of Regular Cannabis Use on Neurocognition in Teens and Young Adults}

\section{Cognition}

Although controversy exists in the adult literature, evidence is building to suggest that regular cannabis use during the teenage or emerging adult years (typically ages 15-25 years) is associated with cognitive deficits [10•]. Two longitudinal studies that followed adolescents with substance use disorders over 8 years found that increased cannabis use during the follow-up period significantly predicted poorer attention 
[11•] and verbal memory [12•]. In the largest prospective, longitudinal study to date, Meier and colleagues [13 ••] followed a sample of 1,037 from birth to age 38 and found that 153 participants met criteria for cannabis-use disorders (CUD) at least once during the follow-up and individuals with more persistent cannabis use demonstrated the greatest reduction in IQ. Specifically, individuals who never regularly used cannabis had a slight increase (0.8 IQ point) in IQ from childhood into adulthood, while those diagnosed with cannabis dependence on at least three or more study occasions had an average loss of 5.8 IQ points. After controlling for gender, nicotine use, comorbid schizophrenia, and alcohol use, they also found specific deficits in executive functioning, sustained attention, verbal list learning, and psychomotor speed associated with persistent cannabis dependence [13••], findings that are generally consistent with cross-sectional studies [10•].

With one exception [14], several cross-sectional studies in cannabis-using youth without psychiatric comorbidities report cannabis-related cognitive deficits including reduced processing speed $[15 \bullet \bullet, 16 \bullet, 17,18 \bullet, 19 \bullet \cdot$, complex attention $[11 \bullet$,

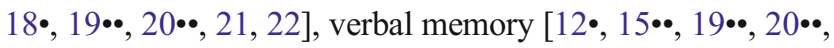
$21,23-26]$, executive functioning $[16 \bullet, 17,18 \bullet, 19 \bullet \bullet, 21-23$, $27,28 \bullet, 29-31]$, and risky sexual behavior [30]. Takagi and colleagues [14] did not find differences in cognitive inhibition on a computerized task between inhalant users, cannabis users, and control adolescents. This may be partially due to a relatively small sample size (19 per group) and the authors did not report specific effect sizes obtained when comparing the cannabis users with controls. Cognitive deficits, including slowed processing speed, reduced verbal memory, sustained attention and sequencing ability, were measured following a month of monitored abstinence in one study [19••], although another found significant recovery following 4 months of abstinence $[15 \bullet \cdot$.

\section{Brain Structure}

\section{Gray Matter}

Several studies to date have demonstrated abnormalities in brain structure in adolescent and emerging-adult cannabis users. In a sample of adolescents (ages 16-19 years) without comorbid psychiatric, developmental, or neurologic conditions, we found that increased past-year cannabis use significantly predicted larger hippocampal volumes [32]. In similar adolescent samples followed over a month of closely monitored abstinence, we found that female cannabis users had larger posterior PFC [33], posterior inferior cerebellar vermis [34], and left amygdala [35] volumes. Male users also had larger posterior inferior cerebellar vermis volumes [34]. Churchwell and colleagues [36] found increased striatal volume in a sample of comorbid cannabis and methamphetamine users. Other groups have reported decreased right medial orbitofrontal cortex [37], reduced hippocampal [38, 39•, 40], reduced amygdala [39•, 40], and increased anterior cerebellar [39॰] volumes in adolescent and young-adult cannabis users without comorbid psychiatric conditions. The above structural alterations in gray matter were associated with increased executive dysfunction [33, 34, 37], mood symptoms [35], poor verbal memory [38], and novelty seeking [36], suggesting that these structural abnormalities were not advantageous. In one of the most thorough structural studies, Lopez-Larson and colleagues [41•] measured cortical thickness in cannabis users and found decreased cortical thickness in right caudal middle frontal, bilateral insula, and bilateral superior frontal cortices with increased thickness in lingual, temporal, inferior parietal, and paracentral areas in the cannabis users compared with non-users. Another novel measurement of gray matter architecture is extent of gyrification, which is formed by horizontal cortical development and increasing tensions in the white matter [42]. Mata and colleagues [43•] found reduced cortical curvature in PFC regions in young adult cannabis users compared with non-using controls, suggesting reduced PFC complexity.

Taken together, these findings suggest that cannabis exposure during the adolescent years may lead to abnormalities in gray matter architecture, including reduced cortical gyrification complexity, increased volume that may reflect disrupted healthy gray matter pruning, and decreased structure that may reflect reduced dendritic branching or neuronal atrophy. Alternatively, increases in volume may be associated with abnormal connectivity patterns in adolescent cannabis users, perhaps reflecting compensation for less efficient cognitive performance. These structural abnormalities and resulting poorer cognitive functioning may signal a delay in neurodevelopment and underlying mechanisms need to be further examined in developmental animal studies.

\section{White Matter}

Containing myelinated axons, white matter is responsible for efficient communication between and within brain regions. Although CB1 cannabinoid receptors are primarily found on neurons, they are also found on myelinating glial cells and are thought to play a significant role in structural connectivity [44]. Advances in diffusion tensor imaging (DTI) allow microstructural measurement of white matter integrity by assessing the extent to which water can diffuse across the axons. Poorer white matter quality is associated with slower processing speed and white matter disease. Structural [45] and micro-structural $[46-48,49 \bullet \bullet, 50,51 \bullet, 52]$ reductions in white matter have also been observed in young cannabis users. Using DTI in a longitudinal study, Bava and colleagues [49・•] found that at the 18-month follow-up, cannabis users with comorbid alcohol use demonstrated poorer white matter integrity in seven tracts (bilateral superior longitudinal 
fasciculus, bilateral thalamic fibers, right superior temporal gyrus, right inferior longitudinal fasciculus, and left posterior corona radiate). However, in this sample, alcohol use during the interscan interval predicted reduced white matter integrity while cannabis did not. With only one exception [50], several studies have now reported reduced white matter quality in several PFC, limbic, parietal and cerebellar tracts in young cannabis users after controlling for alcohol use [46-48, 51 •, $52,53]$. Additional research disentangling the unique effects of alcohol versus cannabis on white matter integrity is needed. In a study examining the relationship between psychological dysregulation, white matter integrity, and substance (including cannabis) use in teens, Clark et al. [53] tested mediation models and concluded that poorer white matter quality in frontoparietal networks was both a risk factor for psychological dysregulation and CUD-related symptoms, and a result of cannabis use.

\section{Blood Flow/Neurochemical}

Adolescent cannabis use has also been associated with reduced cerebral blood flow in PFC, insular, and temporal regions [54] and abnormal neurochemical markers of neuronal integrity $[55 \cdot 56]$. Specifically, magnetic resonance spectroscopy research has shown alterations in glutamate, $\mathrm{N}$-acetyl aspartate, creatine, and myo-inositol in the anterior cingulate [55•], reduced subcortical global myo-inositol/creatine ratios, and reduced white matter myo-inositol [56]. Taken together, these findings suggest that chronic cannabis use during the adolescent and emerging adult years may result in abnormal vascular functioning as well as neuronal and migroglia toxicity. Additional studies are needed to determine whether vascular and glial alterations underlie gray and white matter abnormalities observed in young cannabis users.

\section{Brain Function}

Several studies have reported inefficient brain activation patterns in young cannabis users. Functional magnetic resonance imaging (fMRI) and positron emission tomography (PET) studies that assess brain activation patterns in adolescent cannabis users have reported abnormal PFC, parietal, insular, subcortical/limbic, and cerebellar activation in cannabis users during finger tapping [57•], attentional control [58], spatial working memory $[59,60 \bullet, 61]$, verbal working memory [62, 63•, 64], verbal learning [65], executive functioning [66, 67], and pleasant interoceptive stimuli [68] tasks. In the latter study, findings demonstrated that substance-using teens had blunted processing of pleasant stimuli but heighted sensitivity to reward processing in the insula [68].

In the past couple of years, novel fMRI analyses have revealed abnormal functional connectivity in young cannabis users compared with controls. Increased parietal-cerebellar, right hemispheric, and PFC [69•, 70•] and decreased frontalcerebellar interhemispheric and temporal cortex [70•,71•] resting state connectivity has been reported in adolescent cannabis users. Studies have also found increased functional connectivity between PFC-occipital [72•], and parietalcerebellar [69•] brain regions in adolescent cannabis users while engaging in cognitive tasks. Authors note that observed increased connectivity patterns were associated with increasing task demands and poorer inhibitory control [69•, 72•] and patterns of reduced interhemispheric connectivity complement reports of reduced white matter integrity in these regions [70 $]$. Taken together, these findings suggest that during early cannabis exposure the brain may attempt to compensate by recruiting other neuronal regions, resulting in increased functional connectivity with similar task performance as controls, although such compensation may fail with increased task complexity (e.g., users demonstrate performance decrements in more difficult out-of-scan tasks assessing processing speed, verbal memory, inhibitory control, working memory, and attention; [10•]). Additional longitudinal studies examining how brain connectivity patterns change with increasing use in adolescents and young adults are needed.

\section{Cannabis, FAAH/CNR1 and Neurocognition}

Individual differences in candidate genes related to endogenous cannabinoid signaling such as the cannabis receptor-1 gene $(C N R 1)$ and fatty acid amide hydrolase $(F A A H)$, which are related to CUD risk and healthy brain function (e.g., [73•]), may also moderate the effects of exogenous cannabis exposure on the young brain. Thus far, studies have linked the CNR1 $\mathrm{G}$ allele with reduced bilateral hippocampal volumes [40] and increased cannabis cue-reactivity in PFC-cingulate regions [74], C allele with increased trait anxiety [75], withdrawal and negative affect following abstinence [76], and increased craving following cannabis cues [76] in young adult cannabis users. No links between $C N R 1$ genotype and behavioral problems, impulsivity [75] or amygdala volumes [40] have been found. Cannabis-using carriers of the FAAH C allele have demonstrated greater PFC, cingulate, and nucleus accumbens activation [74] and increased withdrawal [77] and craving [76] symptoms following cannabis cue exposure. $F A A H \mathrm{C}$ allele carriers also demonstrated greater withdrawal and negative affect following abstinence [76]. Results thus far have found no link between FAAH genotype and trait anxiety, impulsivity or behavioral problems [75]. In summary, these preliminary studies suggest that genetics, especially those related to reduced endogenous cannabinoid signaling such as the $F A A H \mathrm{C}$ allele, may place subgroups at greater risk for increased CUD severity and more severe neurocognitive consequences of cannabis exposure. 


\section{Age of Regular Cannabis Use Onset}

Pre-clinical findings demonstrated greater microcellular changes, including altered dopamine, GABA and glutamate signaling, glial cell changes, decreased cAMP response element-binding protein (CREB) signaling in the PFC and hippocampus, abnormal neurotrophic release, and reduced dendritic branching (see [78] for review; [79]), associated with THC (delta-9-tetrahydrocannabinol, the major psychoactive chemical in cannabis) exposure during adolescence compared with adulthood, resulting in increased behavioral effects (e.g., [80-83]). Taken together, animal findings support increased structural alterations that result in poorer memory performance in adolescent THC-exposed animals compared with adults.

In a comprehensive review of human alcohol and cannabis studies, our group [10॰] previously noted increasing evidence that teenage cannabis use onset (CUO) results in greater neurocognitive deficits compared with adult onset. Weekly cannabis use before age 18 has been linked with reduced performance on IQ [13••, 84・•], attention [85], visual search [86] and executive functioning [16•, 17, $31,87 \cdot, 88 \cdot$ neuropsychological tasks. (See Table 1 for overview of studies.)

Perhaps most notable, in their prospective, longitudinal study, Meier and colleagues [13••] reported that adolescents with early CUO had the greatest reduction in IQ, going from a childhood 'average' to an adult 'low-average' IQ. Alarmingly, the individuals with early CUO did not return to their predicted intellectual trajectory. This is consistent with crosssectional studies that have reported greater structural and functional brain abnormalities in early CUO. Wilson and colleagues [89] reported smaller gray matter and increased white matter cortical volumes in adults who initiated regular cannabis use in the teenage versus adult years. Adolescent CUO has also been linked with decreased right superior PFC thickness [41•], reduced PFC white matter integrity, and increased cognitive impulsivity $[51 \bullet, 52]$. With one exception [65], studies examining the impact of early cannabis use on brain function have revealed abnormal blood oxygenation level-dependent (BOLD) activation in PFC and parietal lobes $[16 \bullet, 17,63 \bullet, 64]$. Finally, a recent study reported that dopamine (D2/D3) receptor availability and striatal dopamine release was not abnormal in adults with CUD; however, earlier CUO significantly predicted smaller baseline striatal dopamine release that may explain increased risk of dependence in adolescent CUO [94].

In sum, animal and human studies to date suggest that regular exposure to exogenous cannabinoids may disrupt healthy neurodevelopment, especially in the PFC and parietal cortices $[16 \bullet 17,31,37,41 \bullet, 52,63 \bullet, 87 \bullet]$, which underlie higher-order cognitive functioning. This early initiation during the sensitive period of adolescence may place individuals on a new neurodevelopmental trajectory, resulting in millions of youth who may not reach their full intellectual potential.

\section{Future Research Directions}

\section{Recovery of Function with Abstinence?}

Recently, a PET study demonstrated significant recovery of CB1 receptor downregulation in adult daily cannabis users following 1 month of monitored abstinence [95], suggesting alterations in the endogenous cannabinoid system may recover with abstinence. Still, there is little research that has attempted to answer whether neurocognitive functioning returns with sustained abstinence in youth. In adolescent cannabis users, verbal memory significantly improved following three 3-6 weeks of abstinence [24, 27]. Fried and colleagues $[15 \bullet \cdot]$ demonstrated that adolescent cannabis users no longer had cognitive deficits following 4 months of abstinence $[15 \bullet \cdot]$. Schweinsburg and colleagues [60 $]$ demonstrated that recent cannabis users had greater insular and PFC brain activation compared with ex-users, suggesting inefficient processing may recover with sustained abstinence. Although these brief longitudinal studies demonstrate some recovery, the largest prospective longitudinal study to date reported that individuals who began using cannabis early in the teenage years never fully returned to their predicted pre-drug exposure IQ trajectory, even with abstinence in adulthood [13••]. Therefore, data to date suggests that some cognitive recovery may occur with sustained abstinence although additional prospective longitudinal research is needed to determine whether adolescents who begin regularly using cannabis can recover fully or if their neurocognitive trajectory is permanently altered.

\section{Does Neurocognition Predict Treatment Outcomes?}

Using cannabis may lead to CUD, with $17 \%$ of individuals who tried cannabis before age 17 years becoming dependent (NIDA [96]). In 2010, $49.9 \%$ of all drug treatment admissions reported a CUD, and $86.8 \%$ had an early teenage CUO [97]. Recent studies have attempted to utilize neuroimaging to predict treatment outcomes in youth with early CUO. For example, in a sample of young adolescents (14-17 years old) seeking outpatient treatment for CUD that included psychiatric comorbidities, De Bellis and colleagues [92•] found increased BOLD activation in left superior lobule, lateral occipital, and bilateral precuneus to a risky decision-making task. In the youth with CUD, increased relapse risk and more chronic use was associated with reduced left orbitofrontal activation to reward. In a sample without comorbid psychiatric disorders [91•], decreased BOLD response at baseline in the dorsolateral PFC and anterior cingulate to a stimulus 
response compatibility task, designed to parallel real-world approach-bias (tendency to approach drug-related cues), predicted increased CUD problem severity 6 months later.

In the most integrated translational project to date, Feldstein Ewing and colleagues [93••] utilized fMRI to measure the impacts of psychological treatment (change talk versus counterchange talk) on brain activation to cannabis cues following treatment in teenage cannabis users. They found that change talk increased BOLD activation in areas that underlie introspection (posterior cingulate, precuneaus) during exposure to cannabis cues, and this increase in activation was associated with superior 1-month treatment outcomes (frequency of cannabis use, marijuana-related problems, CUD symptoms). Additional studies utilizing neuroimaging and neurocognitive measures to assess the long-term impact of various treatments on neurocognition and to predict treatment outcomes in adolescent substance users are needed.

\section{Does Content of Cannabis (especially CBD vs THC) Matter?}

There are numerous chemicals in cannabis, including at least 60 cannabinoids. Historically, users have primarily sought plants with high THC content to enhance the subjective 'high,' and a recent analysis of California cannabis revealed that levels of THC are increasing while levels of cannabidiol (CBD) are decreasing [98]. This is of concern as an emerging literature focused on acute exposure is suggesting that increasing the CBD versus THC in cannabis plants may decrease some of the negative effects of use [99], such as anxiety [100, 101], psychotic-like symptoms [101-103], and memory impairment [103, 104]. Further, CBD may moderate effects of THC on affective [100, 102], verbal memory [102], response inhibition [102], visual processing [102], and auditory processing [101, 102] brain activation patterns. Two studies to date have measured THC and CBD levels from hair; one found that individuals with high THC and low CBD had increased symptoms of depression and anxiety [105] and both found worse verbal memory associated with THC, but not CBD $[90 \bullet, 105]$. Further, Demirakca and colleagues [90•] found reduced hippocampal volumes in cannabis users, although increased CBD levels were associated with increased gray matter concentration in bilateral hippocampi. Additional preclinical and human research examining the impact of chronic CBD versus THC exposure on the developing brain is needed, especially as state governments are considering legalization.

\section{Potential Limitations}

Without additional large-scale prospective longitudinal studies, it can be difficult to tease apart the influence of premorbid factors versus direct effects of cannabis exposure on neurocognition in youth. Most of the studies outlined in this review controlled for potentially confounding variables, such as family history of substance use disorders and Axis I disorders; however, subclinical symptoms or neurocognitive correlates of risk factors [27, 53, 106-111] may still explain at least a portion of the brain abnormalities reported in cross-sectional studies of cannabis users. For example, Cheetham and colleagues [112•] found that abnormalities in the orbitofrontal cortex, but not limbic and anterior cingulate areas, predated and predicted the onset of cannabis use in a 4-year, prospective, longitudinal study. Yet, preclinical findings show consistent effects of chronic THC exposure in animal models (e.g., [81]), and the recent large prospective longitudinal study by Meier and colleagues [13••], suggests that reductions in IQ, executive functioning, sustained attention, verbal list learning, and psychomotor speed, areas reportedly impaired in several cross-sectional studies, were related to cannabis exposure after controlling for any premorbid factors. Additional longitudinal research in adolescents prior to cannabis use initiation is needed to determine the specific influence of cannabis exposure on the developing brain.

\section{Conclusions}

\section{Increase Prevention and Treatment}

According to the most recent Monitoring the Future Study, an alarming $6.5 \%$ of high-school seniors smoke cannabis daily, up from $2.4 \%$ in 1993 [1]. This review article summarizes numerous studies that, taken together, suggest regular cannabis use during the adolescent and emerging adult years may disrupt brain function and result in poor cognitive functioning. Even subtle reductions in sustained attention, new learning, psychomotor speed, and executive functioning may result in significant psychosocial consequences during a neurodevelopmental period that is typically rich in new learning and continued education and training. Further, most of the studies examined youth following a period of abstinence and excluded individuals with comorbid disorders; therefore, these findings may underestimate functioning of young cannabis users who may be experiencing withdrawal symptoms, poor sleep quality, comorbid psychiatric symptoms, and stress associated with increased legal issues.

It is becoming increasingly critical to publicize these research findings in any settings that serve adolescents and young adults (e.g., schools, military, mental-health clinics, medical schools, and to parents). It needs to be emphasized that regular cannabis use, defined here as once a week, is not safe and may result in addiction and neurocognitive damage, especially in youth. National websites do produce high-quality education materials outlining the effects of regular cannabis use on the brain and are available for free (e.g., www.nida.nih.gov, www.thecoolspot. gov, www.drugfreeamerica.org, www.Teen-Safe.org). However, psychoeducation alone may not be effective. Additional 
Table 1 Summary of primary findings from human studies reporting neurocognitive effects of regular cannabis use in adolescents and emerging adults (organized by cognitive, structural or functional consequences and clustered according to functional category) (Adapted and modified from [10 $\bullet$ )

\begin{tabular}{lll}
\hline $\begin{array}{l}\text { Cited Neuropsychology findings } \\
\text { cannabis } \\
\text { studies }\end{array}$ & Brain structure findings & $\begin{array}{l}\text { Blood } \\
\text { flow/neurochemistry } \\
\text { findings }\end{array}$ \\
\hline
\end{tabular}

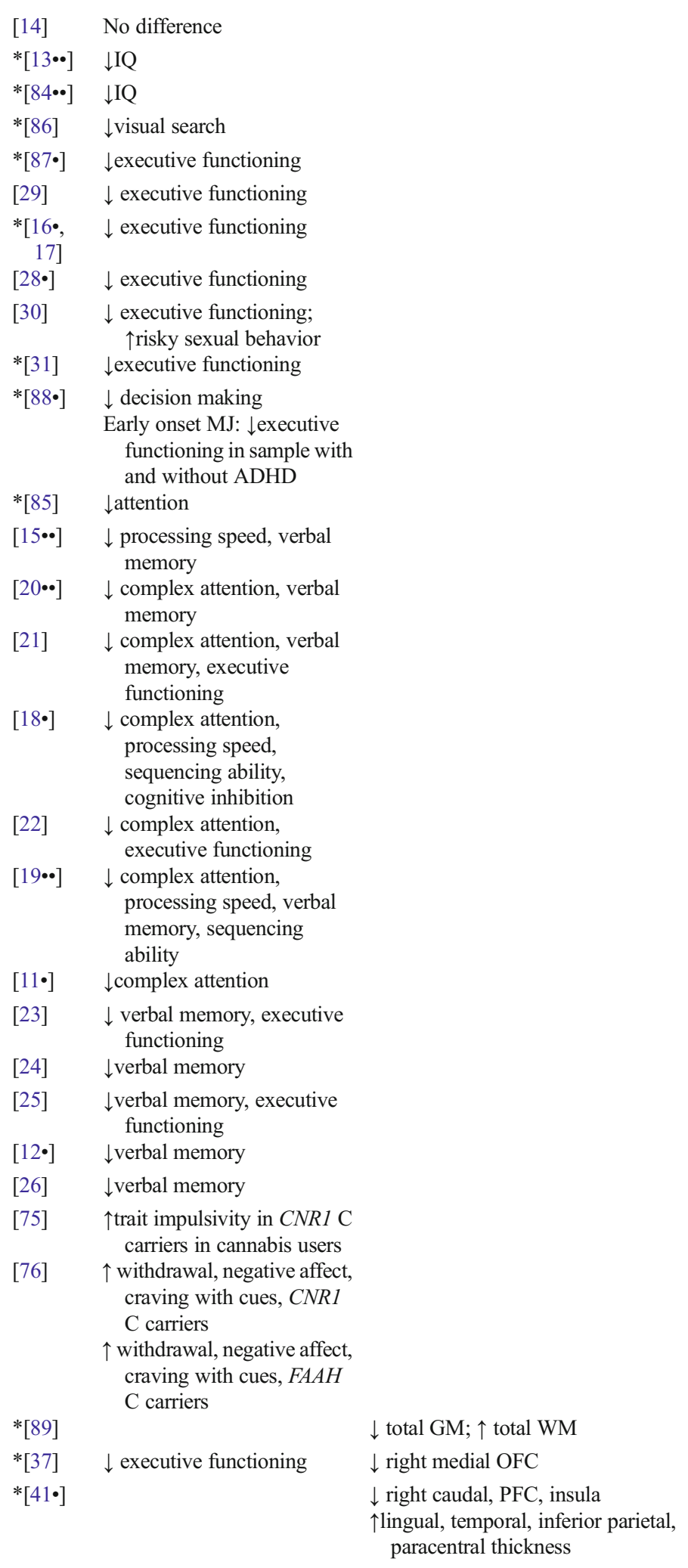


Table 1 (continued)

\begin{tabular}{|c|c|c|}
\hline $\begin{array}{l}\text { Cited } \\
\text { cannabis } \\
\text { studies }\end{array}$ & Neuropsychology findings & Brain structure findings \\
\hline [33] & $\downarrow$ executive functioning & Females: $\uparrow$ inferior PFC volume \\
\hline$[38]$ & $\downarrow$ verbal memory & $\downarrow$ HC volume \\
\hline$[90 \bullet]$ & & $\begin{array}{l}\downarrow \mathrm{HC} \text { volume with } \uparrow \mathrm{THC} \\
\uparrow \mathrm{HC} \text { GM with } \uparrow \mathrm{CBD}\end{array}$ \\
\hline [45] & & $\uparrow$ left $\mathrm{HC}$ volume \\
\hline [35] & $\uparrow$ depressive symptoms & Females: $\uparrow$ left AMYG \\
\hline$[40]$ & & $\begin{array}{l}\downarrow \mathrm{HC}, \mathrm{AMYG} \text { volumes } \\
\downarrow \mathrm{HC} \text { in } C N R 1 \text { G allele }\end{array}$ \\
\hline$[36]$ & $\begin{array}{l}\uparrow \text { novelty seeking in } \mathrm{MJ}+ \\
\text { methamphetamine users }\end{array}$ & $\uparrow$ left putamen volume \\
\hline$[34]$ & $\downarrow$ executive functioning & $\uparrow$ inferior cerebellar vermis volume \\
\hline$[39 \bullet]$ & & $\begin{array}{l}\uparrow \text { GM volume in cerebellum; no WM } \\
\text { differences }\end{array}$ \\
\hline$[50]$ & & No WM differences detected \\
\hline [46] & & $\downarrow$ WM integrity (CC) \\
\hline$[47]$ & & $\downarrow$ WM integrity (arcuate fasciculus) \\
\hline$[48]$ & & $\begin{array}{l}\downarrow \mathrm{WM} \text { integrity in } 10 \text { regions (PFC, } \\
\text { parietal cortex); } \uparrow \mathrm{WM} \text { integrity in } \\
\text { occipital cortex }\end{array}$ \\
\hline$[49 \bullet \bullet]$ & & $\begin{array}{l}\downarrow \text { WM FA in R PFC, thalmic fibers, } \\
\text { plenium, and posterior corona; } \uparrow \\
\text { MD, RD, and AD in } 7 \text { regions }\end{array}$ \\
\hline$*[52]$ & $\uparrow$ impulsivity & $\downarrow$ WM integrity in PFC \\
\hline$*[51 \bullet]$ & $\uparrow$ impulsivity & $\begin{array}{l}\downarrow \mathrm{FA} \text { in } \mathrm{L} \text { and } \mathrm{R} \text { genu of } \mathrm{CC}, \mathrm{L} \\
\text { internal capsule, } \uparrow \text { mean diffusivity } \\
\text { in CC }\end{array}$ \\
\hline$[45]$ & $\uparrow$ depressive symptoms & $\begin{array}{l}\downarrow \text { global WM in MJ users with } \\
\text { depressive sx }\end{array}$ \\
\hline
\end{tabular}

[91•] $\uparrow$ problem severity

$[92 \cdot]$

Blood

Brain function findings

flow/neurochemistry

findings $\downarrow$ blood flow in temporal, insular and $\mathrm{PFC}$ regions

$\downarrow$ ACC glutamate, Nacetyl aspartate, creatine, myoinositol

$\downarrow$ subcortical GM myo-inositol/ creatine; WM myoinositol $\uparrow$ PFC BOLD during attentional control task $\uparrow$ left superior PFC BOLD during working memory task in early onset

$\uparrow$ left parahippocampal BOLD during learning task

$\uparrow$ connectivity in frontal-parietal-cerebellar network in Go/No-Go task; $\uparrow$ connectivity in parietal and cerebellar in RS fMRI

$\downarrow$ PFC and parietal WM FA

$\downarrow$ DLPFC and ACC in heavy users

$\uparrow \mathrm{L}$ superior lobule, lateral occipital cortex, $\mathrm{L}$ and $\mathrm{R}$ precuneus in risky decision-making task

$\uparrow$ insula, parahippocampal, caudate, ACC, and IFG in response to change talk, predicting treatment outcomes 
Table 1 (continued)

\begin{tabular}{|c|c|c|c|c|}
\hline $\begin{array}{l}\text { Cited } \\
\text { cannabis } \\
\text { studies }\end{array}$ & Neuropsychology findings & Brain structure findings & $\begin{array}{l}\text { Blood } \\
\text { flow/neurochemistry } \\
\text { findings }\end{array}$ & Brain function findings \\
\hline$[74]$ & & & & $\begin{array}{l}\uparrow \mathrm{PFC}, \mathrm{ACC} \text {, nucleus accumbens in } F A A H \mathrm{C} \\
\text { carriers }\end{array}$ \\
\hline $\begin{array}{r}*[16 \bullet \\
17]\end{array}$ & & & & $\begin{array}{l}\downarrow \text { ACC fMRI BOLD during inhibition task in } \\
\text { early onset }\end{array}$ \\
\hline$[72 \bullet]$ & & & & $\begin{array}{l}\uparrow \text { PFC and occipitoparietal connectivity as } \\
\text { task demands increase }\end{array}$ \\
\hline$[71 \bullet]$ & & & & $\uparrow \mathrm{PFC}$ activation in RS fMRI \\
\hline$[62]$ & & & & $\begin{array}{l}\downarrow \text { PFC, parietal connectivity during verbal } \\
\text { working memory task }\end{array}$ \\
\hline$[54]$ & & & & $\downarrow \mathrm{CBF}$ in temporal lobe, insula, and PFC \\
\hline$*[63 \bullet]$ & & & & $\uparrow$ PFC BOLD during working memory task \\
\hline$[57 \cdot]$ & & & & $\begin{array}{l}\downarrow \text { ACC, cerebellar BOLD during finger } \\
\text { tapping }\end{array}$ \\
\hline$[68]$ & & & & $\begin{array}{l}\downarrow \text { bilateral posterior insula, R PFC } \\
\uparrow \text { anterior insula to interoceptive stimulation }\end{array}$ \\
\hline [59] & & & & $\begin{array}{l}\downarrow \text { PFC, occipital } \\
\uparrow \text { parietal BOLD during SWM task }\end{array}$ \\
\hline$[60 \bullet]$ & & & & $\begin{array}{l}\uparrow \mathrm{PFC} \text {, insula } \\
\downarrow \text { precentral BOLD during SWM task in } \\
\text { recent MJ users }\end{array}$ \\
\hline$[61]$ & & & & $\begin{array}{l}\uparrow \text { inferior, middle PFC BOLD during SWM } \\
\text { task }\end{array}$ \\
\hline$[66]$ & & & & $\begin{array}{l}\uparrow \text { PFC, parietal, occipital BOLD during } \\
\text { inhibitory task }\end{array}$ \\
\hline$[70 \bullet]$ & & & & $\begin{array}{c}\uparrow \text { right low-frequency and } \downarrow \text { frontal-cerebellar } \\
\text { interhemispheric connectivity in RS fMRI }\end{array}$ \\
\hline$[67]$ & & & & $\begin{array}{l}\text { } \text { ventral medial PFC, cerebellar PET rCBF } \\
\text { during IGT task }\end{array}$ \\
\hline
\end{tabular}

* analysis revealed that teenage cannabis use age of onset $(<16,17$ or 18 years of age) was associated with significantly poorer neurocognitive outcomes. $\uparrow$ increase, $\downarrow$ decrease, $A C C$ anterior cingulate cortex, $A D H D$ attention-deficit hyperactivity disorder, $A M Y G$ amygdala, $B O L D$ blood oxygenation leveldependent, $C B D$ cannabidiol, $C B F$ cerebral blood flow, $C C$ corpus callosum, $D L P F C$ dorsolateral prefrontal cortex, $F A A H$ fatty acid amide hydrolase, $f M R I$ functional magnetic resonance imaging, $G M$ gray matter, $H C$ hippocampus, $I F G$ inferior frontal gyrus, $L$ left, $M J$ marijuana, $O F C$ orbitofrontal cortex, $P E T$ positron emission tomography, $P F C$ prefrontal cortex, $R$ right, $R S$ resting state, $S W M$ spatial working memory, IGT Iowa Gambling task, $T H C$ delta9-tetrahydrocannabinol, $W M$ white matter

prevention research that is effective at delaying the onset of regular cannabis use is needed.

\section{Cannabis Policy Considerations}

Adolescence has been named the "gateway to adult health outcomes" [113] and presents a "golden opportunity for public policy intervention to improve health outcomes that last throughout adulthood" [10•]. The cannabis policy in the US is rapidly changing [114] and two states (CO, WA) have recently legalized cannabis. In order to inform policy, we need further research determining whether specific frequency of use (e.g., >monthly, monthly, weekly, daily) and dose of THC or THC/ $\mathrm{CBD}$ ratios may be considered safe for adults. Additional work is also needed to determine at what age cannabis use is no longer or minimally associated with significant neurocognitive harm (e.g., we know use before 18 is associated with increased neurocognitive deficits, but data is not clear as to whether the age limit should be set at 21 , or closer to 25 when significant gray matter neurodevelopment is complete).

It is estimated that with legalization, cannabis cost will go down and consumption will go up [114] and we have already seen reductions in perceived risk of cannabis in youth [1]. Clearly, we will need additional research to help determine the impact of cannabis legalization or other policy decisions on patterns of use, age of onset, and treatment needs. With easier access to cannabis, it is particularly critical to educate the public about potential health effects of acute and regular use as they relate to youth. It is imperative that the scientific 
community increase dissemination and communication of cannabis-related research findings with policy makers in order to impact critical decisions regarding legal age cut-offs, enforcement of under-age laws, potency decisions (e.g., THC vs CBD ratio), and distribution of prevention and treatment resources as governments begin to consider cannabis legalization. This may be a rare opportunity to help develop policies that can improve public health outcomes (see [114] for discussion of policy considerations).

The largest lessons the scientific community can share are that we need to (i) invest resources to delay the onset of cannabis use past the sensitive period of significant neuromaturation (i.e., close to age 25), (ii) increase resources for prevention, screening, and early intervention for regular cannabis users (especially targeting youth), and (iii) invest in more research regarding the impact of cannabis content and dosage on addiction risk and neurocognition (i.e., following up on preliminary evidence that higher levels of CBD and limiting THC content may reduce public health impact of cannabis use). In order to optimize neuronal development and reduce the prevalence of cannabis use disorders, empirically validated interventions aimed at lowering and preventing cannabis use in youth need to be consistently implemented to minimize the impact of regular cannabis use on the developing brain.

Acknowledgments During manuscript preparation, Dr. Lisdahl was supported by the NIDA-funded grant R01DA030354.

\section{Compliance with Ethics Guidelines}

Conflict of Interest Due to Krista Lisdahl's efforts, the University of Wisconsin-Milwaukee has received money in the form of grants from NIH/NIDA for the current work. Dr. Lisdahl declares consultancy work for the NIH/NIDA and travel, accommodations or meeting expenses paid by INS, APA and NIDA, outside of the submitted work.

Natasha E. Wright, Christopher Medina-Kirchner, Kristin E. Maple and Skyler Shollenbarger declare no conflict of interest.

Human and Animal Rights and Informed Consent This article does not contain any studies with human or animal subjects performed by any of the authors.

\section{References}

Papers of particular interest, published recently, have been highlighted as:

- Of importance

•- Of major importance

1. Johnston LD, O'Malley PM, Bachman JG, Schulenberg JE. Monitoring the Future national results on adolescent drug use: overview of key findings, 2012. Ann Arbor: Institute for Social Research, The University of Michigan; 2013. 83pp.
2. Degenhardt L, Chiu WT, Sampson N, Kessler RC, Anthony JC, Angermeyer M, et al. Toward a global view of alcohol, tobacco, cannabis, and cocaine use: findings from the WHO World Mental Health Surveys. PLoS Med. 2008; 5(7):e141.

3. Giedd JN, Vaituzis AC, Hamburger SD, Lange N, Rajapakse JC, Kaysen D, et al. Quantitative MRI of the temporal lobe, amygdala, and hippocampus in normal human development: ages 4-18 years. J Comp Neurol. 1996;366:223-30.

4. Gogtay N, Giedd JN, Lusk L, Hayashi KM, Greenstein D, Vaituzis AC, et al. Dynamic mapping of human cortical development during childhood through early adulthood. Proc Natl Acad Sci U S A. 2004;101(21):8174-9.

5. Lenroot RK, Giedd JN. Brain development in children and adolescents: insights from anatomical magnetic resonance imaging. NeurosciBiobehav Rev. 2006;30:718-29.

6. Sowell ER, Thompson P, Leonard CM, Welcome SE, Kan E, Toga AW. Longitudinal mapping of cortical thickness and brain growth in normal children. J Neurosci. 2004;24(38):8223-31.

7. Giedd JN, Blumenthal J, Jeffries NO, Castellanos FX, Liu H, Zijdenbos A, et al. Brain development during childhood and adolescence: a longitudinal MRI study. Nat Neurosci. 1999;2: 861-3.

8. Jernigan $\mathrm{T}$, Gamst A. Changes in volume with age: consistency and interpretation of observed effects. Neurobiol Aging. 2005;26(9):1271-4.

9. Spear LP. The behavioral neuroscience of adolescence. Neurosci Biobehav Rev. 2010;24:417-63.

10. Lisdahl KM, Gilbart ER, Wright NE, Shollenbarger S. Dare to delay? The impacts of adolescent alcohol and marijuana use onset on cognition, brain structure, and function. Front Psychiatry. 2013;4(53):1-19. Earlier review article by current author outlining effects of both alcohol and cannabis on the adolescent brain with particular focus on early age of onset.

11. Tapert SF, Granholm E, Leedy NG, Brown SA. Substance use and withdrawal: neuropsychological functioning over 8 years in youth. J Int Neuropsychol Soc. 2002;8(7):873-83. Longitudinal study examining the specific impact of cannabis use on cognition over an 8-year period.

12. Tait RJ, Mackinnon A, Christensen H. Cannabis use and cognitive function: 8-year trajectory in a young adult cohort. Addiction. 2011;106(12):2195-203. Longitudinal study examining the specific impact of cannabis use on cognition over an 8-year period.

13.• Meier MH, Caspi A, Ambler A, Harrington H, Houts R, Keefe RS, et al. Persistent cannabis users show neuropsychological decline from childhood to midlife. Proc Natl Acad Sci U S A. 2012;109(40):2657-64. Largest prospective, longitudinal study examining impact of cananbis use on $I Q$ and cognition.

14. Takagi M, Lubman DI, Cotton S, Fornito A, Baliz Y, Tucker A, et al. Executive control among adolescent inhalant and cannabis users. Drug Alcohol Rev. 2011;30:620-37.

15.• Fried PA, Watkinson B, Gray R. Neurocognitive consequences of marihuana-a comparison with pre-drug performance. Neurotoxicol Teratol. 2005;27(2):231-9. An important longitudinal study examining the impact of cannabis on cognition over time.

16. Gruber SA, Dahlgren MK, Sagar KA, Gönenc A, Killgore WD. Age of onset of marijuana use impacts inhibitory processing. Neurosci Lett. 2012;511(2):89-94. A well designed study examining the impact of early onset cannabis use on neurocognitive functioning, focused on inhibitory control.

17. Gruber SA, Sagar KA, Dahlgren MK, Racine M, Lukas SE. Age of onset of marijuana use and executive function. Psychol Addict Behav. 2012;26(3):486-506. 
18. Lisdahl KM, Price JS. Increased marijuana use and gender predict poorer cognitive functioning in healthy emerging adults. J Int Neuropsychol Soc. 2012;18(4):678-88. Well designed study fully replicating neuropsychological findings from Medina et al., 2007 in different sample.

19.• Medina KL, Hanson K, Schweinsburg AD, Cohen-Zion M, Nagel BJ, Tapert SF. Neuropsychological functioning in adolescent marijuana users: Subtle deficits detectable after 30 days of abstinence. J Intern Neuropsychol Soc. 2007;13(5):807-20. One of the only studies to assess neuropsychological functioning following a closely monitored month of abstinence in adolescents with medium to heavy cannabis exposure.

20.• Hanson KL, Winward JL, Schweinsburg AD, Medina KL, Brown SA, Tapert SF. Longitudinal study of cognition among adolescent marijuana users over three weeks of abstinence. Addict Behav. 2010;35(11):970-6. A well designed study examining cognitive functioning over a 3-week period of closely monitored abstinence.

21. Harvey MA, Sellman JD, Porter RJ, Frampton CM. The relationship between non-acute adolescent marijuana use and cognition. Drug Alcohol Rev. 2007;26(3):309-19.

22. Mathias CW, Blumenthal TD, Dawes MA, Liguori A, Richard DM, Bray B, et al. Failure to sustain prepulse inhibition in adolescent marijuana users. Drug Alcohol Depend. 2011;116(1-3):110-6.

23. McHale S, Hunt N. Executive function deficits in short-term abstinent cannabis users. Hum Psychopharmacol. 2008;23(5): 409-15.

24. Schwartz RH, Gruenewald PJ, Klitzner M, Fedio P. Short-term memory impairment in cannabis-dependent adolescents. Am J Dis Child. 1989;143(10):1214-9.

25. Solowij N, Jones KA, Rozman ME, Davis SM, Ciarrochi J, Heaven PC, et al. Verbal learning and memory in adolescent cannabis users, alcohol users and non-users. Psychopharmacol (Berl). 2011;216(1):131-44.

26. Thoma RJ, Monnig MA, Lysne PA, Ruhl DA, Pommy JA, Bogenschutz M, et al. Adolescent substance abuse: the effects of alcohol and marijuana on neuropsychological performance. Alcohol Clin Exp Res. 2011;35(1):39-46.

27. Hanson KL, Medina KL, Nagel BJ, Spadoni AD, Gorlick A, Tapert SF. Hippocampal volumes in adolescents with and without a family history of alcoholism. Am J Drug Alcohol Abuse. 2010;36:161-7.

28. Gonzalez R, Schuster RM, Mermelstein RJ, Vassileva J, Martin EM, Diviak KR. Performance of young adult cannabis users on neurocognitive measures of impulsive behavior and their relationship to symptoms of cannabis use disorders. J Clin Exp Neuropsychol. 2012;34(9):962-76. A novel study linking cognitive functioning to cannabis use disorder symptoms in youth.

29. Grant JE, Chamberlain SR, Schreiber L, Odlaug BL. Neuropsychological deficits associated with cannabis use in young adults. Drug Alcohol Depend. 2012;121(1-2): 159-62.

30. Schuster RM, Crane NA, Mermelstein R, Gonzalez R. The influence of inhibitory control and episodic memory on the risky sexual behavior of young adult cannabis users. J Int Neuropsychol Soc. 2012;18(5):827-33.

31. Solowij N, Jones KA, Rozman ME, Davis SM, Ciarrochi J, Heaven PC, et al. Reflection impulsivity in adolescent cannabis users: a comparison with alcohol-using and non-substance-using adolescents. Psychopharmacology (Berl). 2012;219(2):575-86.

32. Medina KL, Schweinsburg AD, Cohen-Zion M, Nagel BJ, Tapert SF. Effects of alcohol and combined marijuana and alcohol use during adolescence on hippocampal asymmetry. NeurotoxicolTeratol. 2007;29:141-52.

33. Medina KL, McQueeny T, Nagel BJ, Hanson KL, Yang T, Tapert SF. Prefrontal morphometry in abstinent adolescent marijuana users: Subtle gender effects. Addict Biol. 2009;14(4):457-68.
34. Medina KL, Nagel BJ, Tapert SF. Cerebellar vermis abnormality in adolescent marijuana users. Psychiatr Res Neuroimage. 2010;182(2):152-9.

35. McQueeny TM, Padula C, Price J, Medina KL, Logan P, Tapert SF. Gender effects on amygdala morphometry in adolescent marijuana users. Behav Brain Res. 2011;224(1):128-34.

36. Churchwell JC, Carey PD, Ferrett HL, Stein DJ, Yurgelun-Todd DA. Abnormal striatal circuitry and intensified novelty seeking among adolescents that abuse methamphetamine and cannabis. Dev Neurosci. 2012;34(4):310-7.

37. Churchwell JC, Lopez-Larson M, Yurgelun-Todd DA. Altered frontal cortical volume and decision making in adolescent cannabis users. Front Psychol. 2010;1:225.

38. Ashtari M, Avants B, Cyckowski L, Cervellione KL, Roofeh D, Cook P, et al. Medial temporal structures and memory functions in adolescents with heavy cannabis use. J Psychiatr Res. 2011;45(8): 1055-66.

39. Cousijn J, Wiers RW, Ridderinkhof KR, van den Brink W, Veltman DJ, Goudriaan AE. Grey matter alterations associated with cannabis use: Results of a VBM study in heavy cannabis users and healthy controls. NeuroImage. 2012;59:3845-51. A well designed study examining impact of heavy cannabis use on cortical and subcortical brain structure in chronic cannabis users.

40. Schacht JP, Hutchison KE, Filbey FM. Associations between cannabinoid receptor-1 (CNR1) variation and hippocampus and amygdala volumes in heavy cannabis users. Neuropsychopharmacology. 2012;37(11):2368-76.

41. Lopez-Larson MP, Bogorodzki P, Rogowska J, McGlade E, King $\mathrm{JB}$, Terry J, et al. Altered prefrontal and insular cortical thickness in adolescent marijuana users. Behav Brain Res. 2011;220(1): 164-72. In combination with Lopez-Larson (2012), a very thorough evaluation of how cannabis impacts brain structure in youth.

42. Van Essen DC, Drury HA. Structural and functional analyses of human cerebral cortex using a surface-based atlas. J Neurosci. 1997;17(18):7079-102.

43. Mata I, Perez-Iglesias R, Roiz-Santiañez R, Tordesillas-Gutierrez D, Pazos A, Gutierrez A. et. al. (2010). Gyrification brain abnormalities associated with adolescence and early-adulthood cannabis use. Brain Res. 1317297-304. doi:10.1016/j.brainres.2009.12.069. Novel study examining gyrification, reflecting cortical gray matter complexity, in cannabis users.

44. Moldrich G, Wenger T. Localization of the CB(1) cannabinoid receptor in the rat brain. An immunohistochemical study. Peptides. 2000;21:1735-42.

45. Medina KL, Nagel BJ, McQueeny T, Park A, Tapert SF. Depressive symptoms in adolescents: associations with white matter volume and marijuana use. J Child Psychol Psychiatr. 2007;48(6):592-600.

46. Arnone D, Barrick TR, Chengappa S, Mackay CE, Clark CA, Abou-Saleh MT. Corpus callosum damage in heavy marijuana use: preliminary evidence from diffusion tensor tractography and tract-based spatial statistics. NeuroImage. 2008;41(3): 1067-74.

47. Ashtari M, Cervellione K, Cottone J, Ardekani BA, Sevy S, Kumra S. Diffusion abnormalities in adolescents and young adults with a history of heavy cannabis use. J Psychiatr Res. 2009;43(3): 189-204.

48. Bava S, Frank LR, McQueeny T, Schweinsburg BC, Schweinsburg AD, Tapert SF. Altered white matter microstructure in adolescent substance users. Psychiatr Res. 2009;173(3): 228-37.

49.• Bava S, Jacobus J, Thayer RE, Tapert SF. Longitudinal changes in white matter integrity among adolescent substance users. Alcohol Clin Exp Res. 2013;37(1):181-9. Unique longitudinal study examining impact of cannabis and alcohol use over 18-month follow-up. 
50. DeLisi LE, Bertisch HC, Szulc KU, Majcher M, Brown K, Bappal A, et al. A preliminary DTI study showing no brain structural change associated with adolescent cannabis use. Harm Reduct J. 2006;3:17.

51. Gruber SA, Dahlgren MK, Sagar KA, Gonenc A, Lukas SE. Worth the wait: effects of age of onset of marijuana use on white matter and impulsivity. Psychopharmacology. 2013. doi:10.1007/ s00213-013-3326-z. Combined with Gruber et al. (2012), a well designed study that measures the impact of early onset cannabis use on white matter integrity and cognitive inhibition.

52. Gruber SA, Silveri MM, Dahlgren MK, Yurgelun-Todd D. Why so impulsive? White matter alterations are associated with impulsivity in chronic marijuana smokers. Exp Clin Psychopharmacol. 2011;19(3):231-42.

53. Clark DB, Chung T, Thatcher DL, Pajtek S, Long EC. Psychological dysregulation, white matter disorganization and substance use disorders in adolescences. Addiction. 2012;7(1): 206-14.

54. Jacobus J, Goldenberg D, Wierenga CE, Tolentino NJ, Liu TT, Tapert SF. Altered cerebral blood flow and neurocognitive correlates in adolescent cannabis users. Psychopharmacology (Berl). 2012;222(4):675-84.

55. Prescot AP, Locatelli AE, Renshaw PF, Yurgelun-Todd DA. Neurochemical alterations in adolescent chronic marijuana smokers: a proton MRS study. Neuroimage. 2011;57(1)):69-75. A rare study examining the impact of adolescent cannabis use on neuronal health utilizing MRS.

56. Silveri MM, Jensen JE, Rosso IM, Sneider JT, Yurgelun-Todd DA. Preliminary evidence for white matter metabolite differences in marijuana-dependent young men using 2D J-resolved magnetic resonance spectroscopic imaging at 4 Tesla. PsychiatrRes. 2011;191(3):201-11.

57. Lopez-Larson MP, Rogowska J, Bogorodzki P, Bueler CE, McGlade EC, Yurgelun-Todd DA. Cortico-cerebellar abnormalities in adolescents with heavy marijuana use. Psychiatr Res. 2012;202(3):224-32. One of the most detailed evaluations of brain structural abnormalities in young cannabis users to date.

58. Abdullaev Y, Posner MI, Nunnally R, Dishion TJ. Functional MRI evidence for inefficient attentional control in adolescent chronic cannabis abuse. Behav Brain Res. 2010;215(1):45-57.

59. Schweinsburg AD, Nagel BJ, Schweinsburg BC, Park A, Theilmann RJ, Tapert SF. Abstinent adolescent marijuana users show altered fMRI response during spatial working memory. Psychia Res. 2008;163(1):40-51.

60. Schweinsburg AD, Schweinsburg BC, Medina KL, McQueeny T, Brown SA, Tapert SF. The influence of recency of use on fMRI response during spatial working memory in adolescent marijuana users. J Psychol Drugs. 2010;42(3):401-12. One of a few studies to address effects of abstinence on brain function in cannabis using adolescents.

61. Smith AM, Longo CA, Fried PA, Hogan MJ, Cameron I. Effects of marijuana on visuospatial working memory: an fMRI study in young adults. Psychopharmacol (Berl). 2010;210(3):429-38.

62. Jacobsen LK, Pugh KR, Constable RT, Westerveld M, Mencl WE. Functional correlates of verbal memory deficits emerging during nicotine withdrawal in abstinent adolescent marijuana users. Biol Psychiatr. 2007;61(1):31-40.

63. Jager G, Block RI, Luijten M, Ramsey NF. Cannabis use and memory brain function in adolescent boys: A cross-sectional multicenter functional magnetic resonance imaging study. J Am Acad Child Adolesc Psychiatry. 2010;49(6):561-72. A well designed multi-site study examining brain function in young male cannabis users.

64. Becker B, Wagner D, Gouzoulis-Mayfrank E, Spuentrup E, Daumann J. The impact of early-onset cannabis use on functional brain correlates of working memory. Prog Neuropsychopharmacol Biol Psychiatry. 2010;34(6):837-45.

65. Becker B, Wagner D, Gouzoulis-Mayfrank E, Spuentrup E, Daumann J. Altered parahippocampal functioning in cannabis users is related to the frequency of use. Psychopharmacology. 2010;209(4):361-74.

66. Tapert SF, Schweinsburg AD, Drummond SP, Paulus MP, Brown SA, Yang TT, et al. Functional MRI of inhibitory processing in abstinent adolescent marijuana users. Psychopharmacology (Berlin). 2007;194:173-83.

67. Vaidya JG, Block RI, O'Leary DS, Ponto LB, Ghoneim MM, Bechara A. Effects of chronic marijuana use on brain activity during monetary decision-making. Neuropsychopharmacology. 2012;37(3):618-29.

68. Migliorini R, Stewart JL, May AC, Taper SF, Paulus MP. What do you feel? Adolescent drug and alcohol users show altered brain response to pleasant interoceptive stimuli. DrugAlcohol Depend. 2013;133:661-8.

69. Behan B, Connolly CG, Datwani MC, Ivanovic J, Morioka R, Stone A, et al. Response inhibition and elevated parietal-cerebellar correlations in chronic adolescent cannabis users. Neuropharmacology. 2013;2908(13):241-4. One of the first studies to utilize functional connectivity analysis in adolescent cannabis users.

70. Orr C, Morioka R, Behan B, Datwani S, Doucet M, Ivanovic J, et al. Altered resting-state connectivity in adolescent cannabis users. Am J Drug Alcohol Abuse. 2013;39(6):372-81. A novel study examining resting state functional connectivity in young cannabis users.

71. Houck JM, Bryan AD, Feldstein Ewing SW. Functional connectivity and cannabis use in high-risk adolescents. Am J Drug Alcohol Abuse. 2013;39(6):414-23. A novel study examining functional brain connectivity in young cannabis users.

72. Harding IH, Solowij N, Harrison BJ, Takagi M, Lorenzetti V, Lubman DI, et al. Functional connectivity in brain networks underlying cognitive control in chronic cannabis users. Neuropsychopharmacology. 2012;37(8):1923-33. A novel study examining functional brain connectivity in young cannabis users.

73. - López-Moreno JA, Echeverry-Alzate V, Bühler KM. The genetic basis of the endocannabinoid system and drug addiction in humans. J Psychopharmacol. 2012;26(1):133-43. The most upto-date review on genetics, the endocannabinoid system and addiction in humans.

74. Filbey FM, Schacht JP, Myers US, Chavez RS, Hutchison KE. Individual and additive effects of the CNR1 and FAAH genes on brain response to marijuana cues. Neuropsychopharmacology. 2010;35(4):967-75.

75. Bidwell LL, Metrik J, McGeary J, Palmer RC, Francazio SS, Knopik VS. Impulsivity, Variation in the Cannabinoid Receptor (CNR1) and Fatty Acid Amide Hydrolase (FAAH) Genes, and Marijuana-Related Problems. J Stud Alcohol Drugs. 2013;74(6): 867-78.

76. Haughey HM, Marshall E, Schacht JP, Louis A, Hutchison KE. Marijuana withdrawal and craving: influence of the cannabinoid receptor 1 ( CNR1) and fatty acid amide hydrolase (FAAH) genes. Addiction. 2008;103(10):1678-86.

77. Schacht JP, Selling RE, Hutchison KE. Intermediate cannabis dependence phenotypes and the FAAH C385A variant: an exploratory analysis. Psychopharmacology Berl. 2009;203(3):511-7.

78. Rubino T, Zamberletti E, Parolaro D. Adolescent exposure to cannabis as a risk factor for psychiatric disorders. J Psychopharmacol. 2012;26(1):177-88.

79. Rubino T, Realini N, Braida D, Guidi S, Capurro V, Viganò D, et al. Changes in hippocampal morphology and neuroplasticity induced by adolescent THC treatment are associated with cognitive impairment in adulthood. Hippocampus. 2009;19(8):763-72. 
80. Cha YM, White AM, Kuhn CM, Wilson WA, Swartzwelder HS. Differential effects of delta(9)-THC on learning in adolescent and adult rats. Pharmacol Biochem Behav. 2006;83(3):448-55.

81. Rubino T, Parolaro D. Long lasting consequences of cannabis exposure in adolescence. Mol Cell Endocrinol. 2008;286(1-2 Suppl 1):S108-13.

82. Rubino T, Vigano D, Realini N, Guidali C, Braida D, Capurro V, et al. Chronic delta 9-tetrahydrocannabinol during adolescence provokes sex-dependent changes in the emotional profile in adult rats: behavioral and biochemical correlates. Neuropsychopharmacology. 2008;33:2760-71.

83. Schneider M, Koch M. Chronic pubertal but not adult chronic cannabinoid treatment impairs sensorimotor gating, recognition memory and performance in a progressive ratio task in adult rats. Neuropsychopharmacology. 2003;28:1760-90.

84.•• Pope Jr H, Gruber A, Hudson J, Cohane G, Huestis M, YurgelunTodd D. Early-onset cannabis use and cognitive deficits: what is the nature of the association? Drug Alcohol Depend. 2003;69(3): 303. One of the first papers to address the issue of early cannabis age of onset on neurocognition.

85. Ehrenreich H, Rinn T, Kunert HJ, Moeller MR, Poser W, Schilling L, et al. Specific attentional dysfunction in adults following early start of marijuana use. Psychopharmacology. 1999;142(3):295301

86. Huestegge L, Radach R, Kunert HJ, Heller D. Visual search in long-term cannabis users with early age of onset. Prog Brain Res. 2002;140:377-94.

87. Fontes MA, Bolla KI, Cunha PJ, Almeida PP, Jungerman F, Laranjeira RR, et al. Cannabis use before age 15 and subsequent executive functioning. Br J Psychiatr. 2011;198(6):442-7. A well designed study closely evaluating the impact of early onset cannabis use on executive functioning.

88. Tamm L, Epstein JN, Lisdahl KM, Molina B, Tapert S, Hinshaw SP, et al. Impact of ADHD and cannabis use on executive functioning in young adults. Drug Alcohol Depend. 2013;133(2):60714. One of the only studies to specifically examine combined effects of ADHD and cannabis use on cognitive functioning in emerging adults. This is an important area of research as the effects of cannabis on the brain can mimic symptoms of ADHD (e.g., poor cognitive inhibition, reduced new learning, poorer sustained attention) and individuals with ADHD have an earlier age of cannabis use onset.

89. Wilson W, Mathew R, Turkington T, Hawk T, Coleman RE, Provenzale J. Brain morphological changes and early marijuana use: a magnetic resonance and positron emission tomography study. J Addict Dis. 2000;19(1):1-22.

90. Demirakca T, Sartorius A, Ende G, Meyer N, Welzel H, Skopp G, et al. Diminished gray matter in the hippocampus of cannabis users: Possible protective effects of cannabidiol. Drug Alcohol Depend. 2011;114(2/3):242-5. One of the first studies in human users to examine impact of THC versus CBD effects on the brain.

91. Cousijn J, Goudriaan AE, Ridderinkhof KR, wan den Brink W, Veltman DJ, Wiers RW. Approach-bias predicts development of cannabis problem severity in heavy cannabis users: Results from a prospective FMRI study. PLoS One. 2012;7(9):42394. A novel study examining how brain function relates to cannabis problems in young users.

92. De Bellis MD, Wang L, Bergman SR, Yaxley RH, Hooper SR, Huetel SA. Neural mechanisms of risky decision-making and reward response in adolescent onset cannabis use disorder. Drug Alcohol Depend. 2013;133:134-45. An important study examining decision-making brain response in young cannabis users.

93.• Feldstein Ewing SW, McEachern AD, Yezhuvath U, Bryan AD, Hutchison KE, Filbey FM. Integrating brain and behavior: evaluating adolescents' response to a cannabis intervention. Psychol
Addict Behav. 2013;27(2):510-25. A novel study utilizing fMRI to evaluate effects of behavioral intervention on brain function in adolescent cannabis users.

94. Urban NB, Slifstein M, Thompson JL, Xu X, Girgis RR, Raheja S, et al. Dopamine release in chronic cannabis users: a [11c] raclopride positron emission tomography study. Biol Psychiatry. 2012;71(8):677-83.

95. Hirvonen J, Goodwin R, Li C, Terry G, Zoghbi S, Morse C, et al. Reversible and regionally selective downregulation of brain cannabinoid CB1 receptors in chronic daily cannabis smokers. Mol Psychiatry. 2012;17(6):642-9.

96. National Institute on Drug Abuse. NIDA DrugFacts: marijuana. Washington: National Institute on Drug Abuse, U.S. Department of Health and Human Services; 2012.

97. Substance Abuse and Mental Health Services Administration, Center for Behavioral Health Statistics and Quality. (August 13, 2013). The TEDS Report: Marijuana Admissions Aged 18 to 30: Early vs. Adult Initiation. Rockville, MD.

98. Burgdorf J, Kilmer B, Pacula R. Heterogeneity in the composition of marijuana seized in California. Drug Alcohol Depend. 2011;117(1):59-61.

99. Niesink RM, van Laar MW, Cannizzaro C, Janiri L. Does cannabidiol protect against adverse psychological effects of THC? Front In Psychiatry. 2013;4:130.

100. Fusar-Poli P (2009). S39-01 Distinct effects of D9tetrahydrocannabinol and cannabidiol on neural activation during emotional processing. Euro Psychia. 24.

101. Winton-Brown TT, Allen P, Bhattacharyya S, Borgwardt SJ, Fusar-Poli P, Crippa JA, et al. Modulation of auditory and visual processing by delta-9-tetrahydrocannabinol and cannabidiol: an FMRI study. Neuropsychopharmacology. 2011;36(7):1340-8.

102. Bhattacharyya S, Morrison PD, Fusar-Poli P, Martin-Santos R, Borgwardt S, Winton-Brown T, et al. Opposite effects of delta-9tetrahydrocannabinol and cannabidiol on human brain function and psychopathology. Neuropsychopharmacology. 2010;35(3): 764-74.

103. Englund A, Morrison P, Nottage J, Hague D, Kane F, Bonaccorso S, et al. Cannabidiol inhibits THC-elicited paranoid symptoms and hippocampal-dependent memory impairment. J Psychopharmacol. 2013;27(1):19-27.

104. Morgan CJ, Schafer G, Freeman TP, Curran HV. Impact of cannabidiol on the acute memory and psychotomimetic effects of smoked cannabis: naturalistic study: naturalistic study [corrected]. Br J Psychiatry. 2010;197(4):285-90.

105. Morgan CJ, Gardener C, Schafer G, Swan S, Demarchi C, Freeman TP, et al. Sub-chronic impact of cannabinoids in street cannabis on cognition, psychotic-like symptoms and psychological well-being. Psychol Med. 2012;42(2):391-400.

106. Hill SY, Kostelnik B, Holmes B, Goradia D, McDermott M, Diwadkar V, et al. fMRI BOLD response to the eyes task in offspring from multiplex alcohol dependence families. Alcoholism Clin Exp Res. 2007;31(12):2028-35.

107. Nigg JT, Glass JM, Wong MM, Poon E, Jester JM, Fitzgerald HE, et al. Neuropsychological executive functioning in children at elevated risk for alcoholism: findings in early adolescence. J Abnorm Psychol. 2004;113(2):302-14.

108. Ridenour TA, Tarter RE, Reynolds M, Mezzich A, Kirisci L, Vanyukov M. Neurobehavior disinhibition, parental substance use disorder, neighborhood quality and development of cannabis use disorder in boys. Drug Alcohol Depend. 2009;102(1-3):71-7.

109. Schweinsburg AD, Paulus MP, Barlett VC, Killeen LA, Caldwell LC, Pulido C, et al. An FMRI study of response inhibition in youths with a family history of alcoholism. Ann New York Acad Sci. 2004;1021:391-4. 
110. Spadoni AD, Norman AL, Schweinsburg AD, Tapert SF. Effects of family history of alcohol use disorders on spatial working memory BOLD response in adolescents. Alcohol Clin Exp Res. 2008;32(7):1135-45.

111. Tapert SF, Brown SA. Substance dependence, family history of alcohol dependence, and neuropsychological functioning in adolescence. Addiction. 2000;95:1043-53.

112. Cheetham A, Allen NB, Whittle S, Simmons JG, Yücel M, Lubman DI. Orbitofrontal volumes in early adolescence predict initiation of cannabis use: a 4-year longitudinal and prospective study. Biol Psychiatry. 2012;71(8):684-92. A well designed prospective longitudinal study examining neurocognitive predictors of cannabis initiation.

113. Raphael D. Adolescence as a gateway to adult health outcomes. Maturitas. 2013;75(2):137-41.

114. Caulkins JP, Kilmer B, MacCoun RJ, Pacula RL, Reuter P. Design considerations for legalizing cannabis: lessons inspired by analysis of California's Proposition 19. Addiction. 2012;107(5):865-71. 